NBER WORKING PAPER SERIES

\title{
GENERIC SCRIP SHARE AND THE PRICE OF BRAND-NAME DRUGS: THE ROLE OF CONSUMER CHOICE
}

\author{
John A. Rizzo \\ Richard Zeckhauser \\ Working Paper 11431 \\ http://www.nber.org/papers/w11431 \\ NATIONAL BUREAU OF ECONOMIC RESEARCH \\ 1050 Massachusetts Avenue \\ Cambridge, MA 02138 \\ June 2005
}

We thank Miriam Avins for helpful comments, and Rebecca Friedkin for data management. Friedkin's work was supported by an unrestricted educational grant from the Merck Company Foundation, the philanthropic arm of Merck \& Co., Inc.. The views expressed herein are those of the author(s) and do not necessarily reflect the views of the National Bureau of Economic Research.

(C)2005 by John A. Rizzo and Richard Zeckhauser. All rights reserved. Short sections of text, not to exceed two paragraphs, may be quoted without explicit permission provided that full credit, including $\odot$ notice, is given to the source. 
Generic Scrip Share and the Price of Brand-Name Drugs: The Role of Consumer Choice John A. Rizzo and Richard Zeckhauser

NBER Working Paper No. 11431

June 2005

JEL No. I11, D12, D40

\begin{abstract}
Generic drug utilization has risen dramatically, from $19 \%$ of scrips in 1984 to $47 \%$ in 2001, thus bringing significant direct dollar savings. Generic drug use may also yield indirect savings if it lowers the average price of those brand-name drugs that are still purchased. Prior work indicates and we confirm - that generic competition does not induce brand-name producers to lower prices. However, consumer choices between generic and brand-name drugs could affect the average price of those brand-name drugs that are purchased.

We use nationally representative panel data on drug utilization and costs for the years 1996-2001 to examine how the share of an individual's prescriptions filled by generics affects his average out-ofpocket cost for brand-name drugs. Our principal finding is that a higher generic scrip share lowers average brand-name prices to consumers, presumably because consumers are more likely to substitute generics when the price gap is great. This effect is substantial: a $10 \%$ increase in the consumer's generic scrip share is associated with a $15.6 \%$ decline in the average price he pays for brand-name drugs.
\end{abstract}

John A. Rizzo

Department of Economics

Stony Brook University

Stony Brook, NY 11794

john.rizzo@stonybrook.edu

Richard Zeckhauser

Kennedy School of Government

Harvard University

79 JFK Street

Cambridge, MA 02138

and NBER

richard_zeckhauser@harvard.edu 


\section{INTRODUCTION}

Generic drugs have dramatically increased their presence in the pharmaceutical marketplace; in 2000, $47 \%$ of prescriptions were filled with generic drugs, up from $19 \%$ in $1984 .^{1}$ Generic substitution, beyond saving money directly, can have indirect effects on the prices paid by both consumers and health plans for those brand-name drugs that are still purchased. This could happen in either of two ways: (1) brand-name manufacturers could change their prices in response to competition, or (2) consumers could disproportionately substitute generic drugs for the more expensive (or less expensive) among the brandname drugs, which would lower (or raise) the average purchase price of brand-name drugs.

The competitive and pricing consequences of generic substitution affect consumers, health plans, and drug firms. Understanding these effects also helps to assess legislative efforts, such as the HatchWaxman Act of 1984, which decreased approval times for generics, and for understanding what measures might best curb spiraling pharmaceutical costs without sacrificing health.

Prior work ${ }^{2}$ indicates that brand-name producers do not lower their prices in response to competition with generics. Apparently, drug firms prefer to maintain price while ceding market share to their generic competitors, so that our first indirect effect is not important. These empirical observations are consistent with a two-tiered market, in which price-sensitive consumers switch to the cheaper generics while brand loyalists stick with the higher-priced branded drugs.

However, no past work considers our second indirect effect -- the implicit tradeoffs consumers make between price and perceived quality when choosing among brand-name and generic drugs, tradeoffs

\footnotetext{
1 Pharmaceutical Research and Manufacturers of America. “A Century of Progress.” Washington, DC: Pharmaceutical Research and Manufacturers of America (2001).

${ }^{2}$ Caves, Richard E., Whinston, Michael D., and Hurwitz, Mark A. "Patent Expiration, Entry, and Competition in the U.S. Pharmaceutical Industry." Brookings Papers on Economic Activity: Microeconomics (1991), pp. 1-48; Frank, Richard G., and Salkever, David S. "Generic Entry and the Pricing of Pharmaceuticals." Journal of Economics and Management Strategy. 6 (1997): 75-90; Grabowski, Henry G., and Vernon, John M. "Brand Loyalty, Entry, and Price Competition in Pharmaceuticals after the 1984 Drug Act”. Journal of Law and Economics 35 (1992): 331-350.
} 
that will affect the average price of the brand-name drugs they still purchase. We study this issue by examining the relationship between the share of a consumer's prescriptions that are filled by generics, which we label generic scrip share, and the average price for brand-name drugs purchased by that consumer. Though we focus primarily on prices to consumers -- their copayments (copays) -- we are also concerned with prices to health plans and insurers.

A priori, it is not clear whether greater generic scrip share - which we often abbreviate as scrip share -- should be associated with higher or lower average brand-name prices. A number of plausible hypotheses would predict that a higher generic scrip share would raise the average price that consumers pay for brand-name drugs. This might occur because: I. Consumers' costs differ because their health plans use different copay amounts. Those consumers in geographic areas facing higher copays on average purchase more generics, and also incur higher copays for the brand-name drugs they purchase. II. The prices of brand-name drugs are thought to be correlated with quality, and consumers choose quality over cost, particularly since they pay only a small percent of cost. III. More expensive brand-name drugs tend to be the most heavily advertised, which might make brand loyalty particularly strong for the most expensive of the branded drugs. Any of these three hypotheses predicts a positive relationship between generic scrip share and consumers' costs for their brand-name drugs.

The principal competing hypothesis is that when choosing between generics and brand-name drugs, consumers are primarily motivated by saving money. They will switch to a generic drug when the savings relative to the brand-name price will be high. This price matters hypothesis predicts that a greater generic scrip share would lead to lower average brand-name drug prices to consumers.

Two other players strongly influence drug purchases, physicians and insurers. Doctors play a central role in prescription decisions. We assume that they are loyal agents for their patients, particularly since they have no financial interest in the drugs selected. Health insurers have less direct control over 
prescription choices, but they establish insurance plans that influence those choices. For example, in running their formularies, insurers may induce consumers to purchase generics by using low copays for such drugs. Insurers have a particularly strong incentive to encourage patients to buy generic versions of expensive brand-name drugs. Whatever the instrument, insurers provide incentives that affect the nature and extent of consumer switching from brand-names to generics. This in turn will affect the average price that they and their consumers pay for brand-name drugs. Plans may also pressure the physicians who work for them or are on their approved list to prescribe generic drugs where possible.

Below, we shall also investigate how generic scrip share affects the average price that health plans pay for brand-name drugs. If health plans structure their formularies and copays so that the more expensive brand-name drugs are generally more expensive to consumers, we would expect savings for consumers to translate into savings for health plans.

On the other hand, it is quite possible that plans might not save money even if consumers do. Consider two possibilities. First, there may be many expensive drugs, such as new and patented introductions, that are made available with low copays because there are no generic substitutes. Ultimately, health plans are agents for consumers, and even if they are profit maximizers, market forces push them toward faithful agency. Given that, expensive brand-name drugs that have no substitutes will have moderate copays. Second, within a copay category, higher priced brand-name drugs may offer or may be perceived as offering higher quality. If so, quality-concerned consumers will buy generics primarily to replace the cheaper brand-name drugs in each category. For the insurer, this represents a form of adverse selection; it pays disproportionately for higher-priced brand-name drugs. In that case, consumer cost savings from the mix of brand-name drugs purchased would not translate into plan cost savings. 
We conduct our analysis using a nationally representative panel of data on drug utilization and costs for the years 1996-2001. We compute the effect of changes in the shares of generic scrips on the average out-of-pocket cost for brand-name drugs purchased by a consumer with health insurance, and the net cost paid by the insurer. ${ }^{3}$

We wish to determine how consumers' generic drug purchases affect the average prices of the brand-name drugs they also purchase. To forestall speculation that other factors may be more important, we mention two more results, which are reported in Appendix B. First, leaving aside consequences that work through consumers' own shares of generic purchases, we find no evidence that market-level measures of generic scrip share affect average brand price. This finding -- that firms do not respond on a geographic basis to generic scrip share -- complements the work cited above suggesting that firms do not lower price. It also indicates that the behavior of drug firms does not explain our primary result.

Second, if brand drugs that face generic competition tend to be more expensive, an association between generic scrip share and lower average brand price might not reflect any systematic consumer choice, but merely that generics replace relatively expensive brand-name drugs. We examined this issue by looking at a representative sample of commonly dispensed brand-name drugs with and without generic substitutes. We found that brand-name drugs with generic substitutes were generally less expensive both to plans, and on an out-of-pocket basis to consumers. This factor alone would suggest that a higher generic scrip share would be associated with higher brand-name prices. Thus, an empirical finding of a negative relationship between generic scrip share and brand name prices would suggest that other factors - such as consumer choice in response to price - are at work.

The remainder of this paper is divided into six parts. Part I provides descriptive background, and reviews the evidence on generic scrip share and the price of brand-name drugs. Our conceptual model of how consumers choose whether to buy brand-name or generic drugs is presented in Part II. Part III

\footnotetext{
${ }^{3}$ Insurer costs here are the costs paid by the insurer, net of any copays or coinsurance paid by the consumer.
} 
presents our hypotheses. Part IV describes the data and empirical models to be estimated. The results are presented in Part V. Part VI summarizes the results and their policy implications.

\section{GENERIC SCRIP SHARE AND BRAND-NAME DRUG PRICES}

Background

Pharmaceuticals account for a significant share of health care expenditures in the United States, ranking third after hospital care expenditures and expenditures on physician services. In 2000, for example, hospital care accounted for $32.8 \%$ of health care expenditures in the United States, physician services accounted for $22.8 \%$, and $9.7 \%$ of expenditures - nearly $\$ 122$ billion, or $\$ 450$ per person -- were incurred for pharmaceuticals ${ }^{4}$

In absolute terms, pharmaceutical costs quadrupled between 1990 and 2002, ${ }^{5}$ but also rose as a share of overall health care expenditures. Drug expenditures accounted for $5.1 \%$ of total health care expenditures in 1980 , and $5.9 \%$ by 1995 . They then exploded to $9.7 \%$ by $2000 .{ }^{6}$ Some combination of increases in prices, growth in volume, and changes in the mix of pharmaceutical products explains this dramatic growth. In recent years, contrary to popular perceptions, price increases played a small role in explaining the growth in pharmaceutical expenditures. As Berndt ${ }^{7}$ notes:

... from 1987 through 1994, price growth at 6.1 percent annually was responsible for slightly more than half of the 11.9 percent sales growth. However, from 1994 through 2000, price growth accounted for only about one-fifth of revenue growth ( 2.7 percentage points out of 12.9 percent).... in recent years, price increases have been relatively less important, and instead, quantity growth -greater utilization of incumbent and new products-- has been the primary driver of increased spending.

\footnotetext{
${ }^{4}$ Berndt, Ernst R. "Pharmaceuticals in U.S. Health Care: Determinants of Quantity and Price." Journal of Economic Perspectives 16 no. 4 (2002): 45-66.

${ }^{5}$ Kaiser Family Foundation. "Prescription Drug Trends." Washington, DC: Kaiser Family Foundation (2004).

${ }^{6}$ See Berndt, supra note 4.

${ }^{7}$ See Berndt, supra note 4, pp. 46-47.
} 
The Hatch-Waxman Act of 1984 created an abbreviated approval process for generic drugs while extending the patent length of brand-name drugs.

$\ldots$ the act increased the proportion of brand-name drugs that face generic competition once their patents expire. In 1983, only 35 percent of the top-selling drugs with expired patents (excluding antibiotics and drugs approved before 1962) had generic versions available. Today, nearly all do. ${ }^{8}$

In addition, changes in state laws and third party payer initiatives have promoted greater use of generic drugs, which made up $47 \%$ of scrips in $2000 .{ }^{9}$ For example, 40 states allow pharmacists to substitute generics unless otherwise directed by physicians. ${ }^{10}$ Third party payers have changed copay structures to encourage consumers to purchase more generics.

Despite these policy changes, a number of barriers to greater use of generic drugs in the United States persist. ${ }^{11}$ Some have argued, for example, that current federal laws governing patent protection and intellectual property rights provide excessive patent protection for brand-name drugs, since they allow brand-name producers to file additional patents just as their old patents are about to expire, thereby extending the life of the initial drug. Current laws also impose delays on generic competition when patent disputes arise. In addition, brand and generic companies may reach settlements, the terms of which include delayed entry of generics. ${ }^{12}$

Another practice, known as "evergreening," involves repackaging and reformulating a brand-name drug as its patent is about to expire. A common method of evergreening

\footnotetext{
${ }^{8}$ Congressional Budget Office. "How Increased Competition from Generic Drugs Has Affected Prices and Returns in the Pharmaceutical Industry." Washington, DC: Congressional Budget Office (1998), p. ix.

${ }^{9}$ See Pharmaceutical Research and Manufacturers of America, supra note 1.

${ }^{10}$ Forty-one states also have provisions that consumers must give consent or be informed of any generic substitution See: NIHCM Foundation (National Institute for Health Care Management Research and Educational Foundation). "A Primer: Generic Drugs, Patents, and the Pharmaceutical Market Place.” Washington, DC: NICHM Foundation (2002), p. 23. Accessed at: http://www.nihcm.org/GenericsPrimer.pdf.

${ }^{11}$ The discussion in this section draws upon a study of generic drugs and patents by The NIHCM Foundation, supra note 10, to which the reader is referred for further discussion of the issues raised herein.

${ }^{12}$ This practice has, however, attracted scrutiny by government regulators:

The Federal Trade Commission (FTC) is currently probing whether and when such settlements violate antirust law. Several drug companies have already been required to abide by FTC consent decrees that bar them from making such arrangements.
} 
...is to produce an "extended release" form of a drug whose patent is just about to expire. These new formulations may have to be taken once every few days or even once a week instead of every day. Such new formulations win three years of patent protection (for the new formulation but not the "mother drug"). When the patent on the mother drug expires and generics of it become available, the brand company wages a marketing campaign to switch users to the extended release form of the drug. ${ }^{13}$

While these minor changes may confer benefits on some patients, it is also possible that some patients may be switched inappropriately to these reformulated drugs, whose prices will remain substantially higher than the generics. In addition, brand-name producers have voiced concerns about the bioequivalence of generic drugs, and have questioned the quality of their production methods, presumably in part to sow doubt among consumers.

A provision in the Omnibus Budget Reconciliation Act of 1990 (OBRA 1990) raises another potential barrier. This law requires brand-name firms to offer $15 \%$ discounts to the program to receive federal payments under Medicaid. But in return the law prohibits state Medicaid programs from removing these brand-name drugs from their formularies so long as they continue to offer the discount. This leads critics to "allege that this structure prohibits states form evaluating drugs more aggressively and undermines the wider use of less expensive generics."

The principal instrument discouraging generic use relative to what a fully informed free market would produce is widespread insurance for pharmaceutical expenditures. Under such plans, consumers pay only a portion of the cost differential between brand-name and generic drugs, often a quite modest portion. Their larger subsidy gives brand-name drugs a competitive advantage. ${ }^{15}$

Growth in generics relative to brand-name drugs appears to have leveled off in recent years, perhaps due to these obstacles. Between 1996 and 2000, the generic share of total scrips has grown more

This has led some drug company analysts to speculate that the practice will decline. See NIHCM Foundation, supra note 10, p. 23.

${ }^{13}$ See NIHCM Foundation, supra note 10, p. 23.

14 See NIHCM Foundation, supra note 10, p. 25. 
slowly, from $43 \%$ to $47 \%{ }^{16}$

\section{$\underline{\text { Price competition }}$}

Generic drugs are typically offered to insurance plans at substantially lower prices than their branded counterparts. Evidence suggests that an initial generic entrant is priced at about $75 \%$ of the price of its brand-name competitor; with subsequent generic entrants, the prices of generics decline rapidly. ${ }^{17}$ Moreover, managed care organizations and pharmacy benefits management companies negotiate price discounts from drug manufacturers. Thus strong price discounts for generics and the desire to remain in good favor with large purchasers such as managed care organizations would seem to create powerful incentives for producers of brand-name drugs to compete on price.

Yet price competition may be affected by a variety of other considerations, including the presence of health insurance covering drugs, consumer uncertainty about both the prices and quality of brand-name drugs and generics, brand-name advertising, and the costs of drug development. The insurance subsidy allows consumers to focus more on quality relative to price than they otherwise would. Thus, health insurance coverage may dampen consumer sensitivity to price, lowering incentives for producers of brand-name drugs to compete on price with generics.

Evidence suggests that neither physicians nor patients are generally knowledgeable about the prices of drugs and medical treatments ${ }^{18}$ this could further dampen incentives for producers of branded

\footnotetext{
${ }^{15}$ An efficient market would offer insurance against needing a drug. However, where generic substitution was possible, it would have the marginal cost of choosing a brand-name drug over a generic borne by the consumer.

16 See Pharmaceutical Research and Manufacturers of America, supra note 1.

${ }^{17}$ Meier, Markus H. “The FTC's Pharmaceutical Industry Cases.” California Bar Association (2002). Document available at: www.calbar.ca.gov/calbar/pdfs/sections/antitrust/2002-06-26_generic-drug_materials-meier.pdf.

${ }^{18}$ Gaynor, Martin, and Polachek, Solomon W. "Measuring Information in the Market: An Application to Physician Services." Southern Economic Journal 60 no. 4 (1994): 815-831; Hibbard, Judith H., and Weeks, Edward C. "Consumerism in Health Care: Prevalence and Predictors." Medical Care 25 no. 11 (1987): 1019-1032; Hibbard, Judith H., and Weeks, Edward C. "Does the Dissemination of Comparative Data on Physician Fees Affect Consumer Use of Services?" Medical Care 27 no. 12 (1989): 1167-1174; Silcock J, Ryan M, Bond C, et al. (1997). "The Cost of Medicines in the United Kingdom: A Survey of General Practitioners' Opinions and Knowledge." PharmacoEconomics 11 no. 1 (1997): 56-63.
} 
drugs to lower their prices. Moreover, while generics are touted as being equivalent to their brand-name counterparts, consumers may not be able to gauge whether such claims are true, particularly since it is often alleged that generics are inferior. And producers of brand-name drugs - which typically spend heavily on marketing efforts - have the incentive to convey messages to consumers that generics offer inferior quality.

Finally, producers of brand-name drugs face far higher production costs than do producers of generics, once their very expensive R\&D, approval, and marketing costs are factored in. Moreover, brand-name producers typically have a limited number of drugs on the market to recoup the R\&D costs, including costs for the very large number of potential drugs that never make it to market. Producers of branded drugs tend to maintain prices despite competition from generics, presumably hoping to separate the market by elasticity. To facilitate this separation, they undertake expensive marketing efforts to hold onto as many of their brand- loyal customers for as long as possible.

\section{Empirical evidence on drug pricing in response to generic scrip share}

To our knowledge, there is no literature on how the share of generic scrips affects the average prices of the brand-name pharmaceuticals that are purchased. However, a number of studies have examined a related issue, the effect of generic entry on brand-name prices. While it is clear that generic entrants often capture significant market share, ${ }^{19}$ most evidence indicates that generic competition has little effect on the prices of brand-name drugs. Grabowski and Vernon ${ }^{20}$ studied 18 drugs that lost patent protection between 1983 and 1987, and found that brand-name prices continued to rise faster than inflation following generic entry. Frank and Salkever ${ }^{21}$ examined 32 drugs that went off patent between 1984 and 1987, and determined that brand-name prices increased slightly following generic entry - by

\footnotetext{
19 See Pharmaceutical Research and Manufacturers of America, supra note 1.

20 See Grabowski and Vernon, supra note 2.

${ }^{21}$ See Frank and Salkever, supra note 2.
} 
about one extra percentage point for each generic entrant. Caves et al. ${ }^{22}$ examined 30 brand-name drugs that went off patent between 1976 and 1987, and found that generic scrip share reduced the prices of branded drugs, but only by about 2 percent. A study by the Congressional Budget Office ${ }^{23}$ of 34 drugs that lost patent protection after 1991 concluded that the prices of these drugs continued to rise faster than inflation following generic entry, thus providing little evidence that such entry promoted price competition.

The lone study finding different results is by Wiggins and Manness, ${ }^{24}$ who report substantial price reductions among brand-name anti-infective drugs following generic entry. Some have argued, however, that the anti-infective market has unusually vigorous competition (Office of Technology Assessment 1993; Grabowski and Vernon 1992). ${ }^{25}$

\section{CONCEPTUAL FRAMEWORK}

We begin by considering a situation where consumers or their doctor agents primarily determine whether to purchase generic or brand-name drugs. (In this analysis, we use the terms consumer, individual and patient interchangeably.) The availability of generics affords the consumer greater choice. He can tilt the mix of his drug purchases toward cheaper generic equivalents. Whether he does so will depend on any concerns he has that brand-name drugs offer superior quality. Such concerns will be reinforced by advertising efforts by brand-name incumbents.

\footnotetext{
22 See Caves et al., supra note 2.

${ }^{23}$ See Congressional Budget Office, supra note 8.

${ }^{24}$ Wiggins, Steven N., and Maness, Robert S. "Price Competition in Pharmaceuticals: The Case of Anti-infectives." Economic Inquiry 42 no. 2 (2004): 247-263.

${ }^{25}$ See Grabowski and Vernon, supra note 2; Office of Technology Assessment. "Pharmaceutical R\&D: Costs, Risks and Rewards ." Washington, DC: Office of Technology Assessment (1993).
} 
Switching costs may also deter the consumer from choosing a generic drug. These include the monetary and time costs of a physician visit to request a change in medication, and the costs of gathering information about the availability and suitability of generic substitutes. Switching costs may also include a psychic component as well, due perhaps from lingering uncertainty that the generic drug might not be as safe or effective; advertising efforts by branded incumbents may reinforce such concerns.

In markets where generic scrip share is great, switching should be more common. That is because information about generics is likely to be more readily available, and because the greater use of generics should decrease transactions costs associated with switching. For example, physicians will be more aware of generics, and pharmacies more likely to carry them. In essence, we are arguing that the greater availability of generic drugs conveys positive externalities to those contemplating a switch to them.

Our principal concern in this essay is whether greater use of generic drugs by a consumer will raise or lower the average price of the brand-name drugs individuals continue to buy. To foster intuition, consider a situation where a consumer needs two drugs. Their respective brand-name versions have different copays, and a generic substitute is available for each. Some exogenous factor has made generics relatively more attractive than they were before. For which of the two brand-name drugs will the consumer purchase a generic substitute first? To answer this question, we must model the factors affecting the consumer's decision to switch from brands to generics.

To begin, insurers almost always offer the consumer a lower copay for generic drugs, which favors generics. However, consumers will also consider the quality of the drug, which may be a counterbalancing advantage for brand-name drugs. Drug quality has two components: (1) the drug's safety and effectiveness for its purpose, and (2) the importance of its purpose.

Relating to (1), leaving price aside, we would assume that consumers are more likely to buy brand-name drugs if they assume that brand-name drugs are substantially safer or more effective than 
generic drugs. This might advantage well-known brands, or drugs that are known to be high-tech developments. Component (2) would suggest that a consumer would be more likely to use a brand-name drug than a generic for a life-threatening condition than for a skin rash. Indeed, survey evidence indicates that consumers perceive quality differentials between brand-name drugs and generic substitutes to be greater when the drugs are used to treat more serious conditions. ${ }^{26}$

We denote the two elements of concern as $C$ for copay and $Q$ for quality, where the latter incorporates both quality components. There are two brand-name drugs, denoted by superscripts $H$ and $L$, that respectively have high and low copays. The terms "brand-name" and "generic" are indicated by the subscripts $b$ and $g$. To ease exposition, we shall assume that quality is scaled so as to be linear with money, and that money and quality are separable and additive elements in the utility function. Let overall wealth be $W$.

An individual's utility can thus be represented as

$$
(\mathrm{W}-\mathrm{C})+\lambda \mathrm{Q}
$$

where $\lambda$ represents the shadow value of quality. ${ }^{27}$ Since copays are low relative to overall wealth, we shall assume that income effects are small and omit $W$ from future expressions. The critical issue in deciding whether to purchase a brand-name or generic drug is how much money will be saved, and how much quality will be sacrificed. If the ratio of savings to sacrifice is great, individuals will tip toward generics, and vice versa. The critical expression, derived from (1), is

$$
\left(\mathrm{C}_{\mathrm{b}}-\mathrm{C}_{\mathrm{g}}\right) /\left(\mathrm{Q}_{\mathrm{b}}-\mathrm{Q}_{\mathrm{g}}\right)=\lambda_{\mathrm{i}}
$$

\footnotetext{
${ }^{26}$ For example, Ganther and Kreling report that subjects viewed generic substitution as most risky when treating heart ailments (54\%) and least risky when treating strep throat (14\%). See Ganther, Julie M., and Kreling, David H. (2000). “Consumer Perceptions of Risk and Required Cost Savings for Generic Prescription Drugs." Journal of the American Pharmacy Association 40 (2000): 378-383. For a review of the literature on this subject, see Gaither C, Kirking D, Ascione F, et al. “Consumer's Views on Generic Medications." Journal of the American Pharmacy Association 41 no. 5 (2001): $729-736$.
} 
where $i$ indexes consumers. For individual $i$, this gives a situation where the cost difference between the brand-name and generic drugs is just compensated by the perceived quality differential. If the ratio on the left in (2) exceeds $\lambda_{i}$, consumer $i$ should purchase the generic, whereas the brand-name should be purchased if the inequality is reversed. ${ }^{28}$

Consumers with high generic use presumably have a small positive value of $\lambda$; i.e., cost differences matter a lot. ${ }^{29}$ Our interest is whether such consumers tend to have a brand-name mix that is richer or poorer in $H$ (high copay) drugs. A critical consideration will be the differences in the perceived qualities of $H$ and $L$ drugs and their generic substitutes. Take the case where the brand-generic quality differential for $H$ drugs is perceived to be similar to that for $L$ drugs. Then the expression in (2) will be larger for $H$ drugs than for $L$ drugs because absolute out-of-pocket cost differentials between high-cost brand-name drugs and their generic equivalents will tend to be larger for the consumer, ${ }^{30}$ which makes it more likely to be greater than the critical value $\lambda$ for any particular consumer. This situation will continue to be true if some consumers perceive greater quality differences between brand-name and generic drugs than do others. In either case, looking across individuals, there will be proportionally more generic substitution for $H$ drugs. More money is saved, but the quality sacrifice is little or no greater.

Consider now a situation where $H$ drugs are assumed by consumers to offer noticeably higher quality. This perception could apply for a number of reasons: (1) Consumers are used to thinking that higher priced items are of higher quality. (2) Drug companies - thinking in elasticity terms -- may charge more for high quality drugs, including those dealing with dreaded conditions, particularly for those for

\footnotetext{
${ }^{27}$ Even if individuals have strictly convex indifference curves, they will be operating locally as if there is a linear tradeoff between money and quality.

${ }^{28}$ Note, when there is no difference in perceived quality the denominator is 0 , the ratio is infinite, and the generic is purchased if its out-of-pocket price is below that for the brand-name drug.

${ }^{29}$ High generic drug use could also reflect a situation where a consumer saw little or no quality difference between brand-name and generic drugs. In that case, as when $\lambda$ is small, price is the primary driver of generic drug purchases.

${ }^{30}$ This will be true if as seems reasonable, the higher-priced brand drugs involve higher copays than the lower-priced brand drugs, but there is little difference in the copays associated with their respective generic equivalents.
} 
which generics substitutes have different formulations or are believed to be inferior. (3) Drug companies do more direct-to-the-consumer marketing of higher-priced drugs. If health plans impose higher copays for drugs that cost them more, then higher copays will associated with higher quality.

In assessing quality and cost tradeoffs, the critical comparison is between the ratio in (2) for brand-name drug $H$ and brand-name drug $L$. That comparison is:

$$
\left(\mathrm{C}_{\mathrm{b}}{ }^{\mathrm{H}}-\mathrm{C}_{\mathrm{g}}{ }^{\mathrm{H}}\right) /\left(\mathrm{Q}_{\mathrm{b}}{ }^{\mathrm{H}}-\mathrm{Q}_{\mathrm{g}}{ }^{\mathrm{H}}\right) \text { and }\left(\mathrm{C}_{\mathrm{b}}{ }^{\mathrm{L}}-\mathrm{C}_{\mathrm{g}}{ }^{\mathrm{L}}\right) /\left(\mathrm{Q}_{\mathrm{b}}{ }^{\mathrm{L}}-\mathrm{Q}_{\mathrm{g}}{ }^{\mathrm{L}}\right)
$$

Our formulation assumes the consumer has different views of the qualities of the four drugs involved, which are indexed by $b$ and $g$ and also by $H$ and $L$. (Though we allow the copay for the generic substitute to vary for $H$ and $L$, we generally think these costs will be the same.)

If the left ratio in (3) is less than the right ratio, then if $\lambda$ lies between the two, the individual will

substitute a generic for $L$, but buy brand-name $H$. In such a world, we would see more prescriptions filled by generics accompanied by higher average brand-name prices. In other words, if brand-name $H$ drugs are perceived to offer much greater quality gains over generics than do brand-name $L$ drugs, more generics will mean higher brand-name copays on average. The converse implication is also true.

The actual relationship between generic scrip share and brand prices is an empirical issue and the focus of this paper. The following section clarifies the hypotheses we test.

\section{HYPOTHESES}

One central question motivates the hypotheses that we will set forth: what factors are most important in determining whether consumers or their physicians decide to purchase a generic or brandname drug? While the consumer-doctor dyad chooses the drug, the health plan influences their choice through both copayment arrangements and the drugs it lists on the formulary. Moreover, we assume that the combination of market forces plus some extension of the Hippocratic Oath assure that the health plans 
are reasonably reliable agents for their patients. Presumably, since the health plan offers both brandname drugs and generic substitutes for them when available, it believes there is little or no difference in quality between a brand-name drug and generic alternatives. In some cases, and almost always when brand-name drugs have gone off patent, the two drugs have precisely the same formulation. One example is Capoten, a brand-name antihypertensive drug and its generic equivalent, captopril. In other circumstances, the generic and brand-name drugs are considered therapeutically equivalent, but may differ in ingredients or mechanism of action. An example would be the branded antihypertensive drug Lotensin, still under patent, and the generic antihypertensive captopril.

Our principal hypotheses assume that the patient selects drugs utilizing a decision model in the spirit of the one spelled out in Section II. The hypotheses apply equally well if the physician is the predominant decision maker or a collaborative decision maker, assuming that the physician is acting as an effective agent for the patient. Such a doctor will take account of both the patient's copays and his concern about drug quality.

Our first hypothesis is that differences in generic scrip share are primarily driven by differences in costs consumers face for brand-name drugs across geographic areas, e.g., because of variability in insurance plans across areas. When consumers face high out-of-pocket costs for such drugs, both substitution and income effects will encourage them to buy more generics.

Hypothesis I: Differences in brand-name prices to consumers drive generic use. The higher are the out-of-pocket costs for brand-name drugs, the more generics a consumer will purchase. Hence, looking across geographic areas, there will be a positive relationship between the average brand-name prices to a consumer and the likelihood that he purchases a generic drug. This will be particularly true if most brandname drugs - weighted by volume of use - on a plan have similar or identical copays. 
Our second consumer welfare hypothesis is a compound hypothesis. First, patients are more concerned with quality than with price. Second, the price to consumers of a pharmaceutical is either an actual indicator or a perceived indicator of quality.

Hypothesis II: Quality matters greatly; brand-name prices indicates quality. Since consumers are more concerned with quality than price, and presume a positive correlation between the two, they will tend to substitute generics for those brand-name drugs whose price to them is low. Hence, increased levels of generic scrip share - assumed to be caused by independent factors -- will be accompanied by a rise in the average brand-name price paid by consumers.

Our third hypothesis is also compound. First, drug companies market more expensive brand-name drugs more heavily -- whether to doctors or in direct-to-consumer advertising -- because there is more to gain from a single sale and from continued brand loyalty. Second, health plans in effect set higher copays for more expensive brand-name drugs -- disproportionately those that are heavily advertised -- either to recoup costs or discourage their use.

Hypothesis III: Drug company advertising deters generic purchases. Drug companies will be highly reluctant to lose customers to generics for brand-name drugs with high prices. Hence, they will differentially advertise those drugs, and thereby discourage sales of their generic substitutes. Assuming that health plans set generic copays that vary positively with drug prices, generic drugs will substitute for lower-priced brand-name drugs, and greater generic scrip share will raise the average price of brand-name purchases. $^{31}$

Implication of Hypotheses I-III. Hypotheses I - III all predict that greater generic scrip share will be associated with higher average prices to consumers for brand-name drugs. If that prediction is

\footnotetext{
31 This hypothesis would also apply if expensive brand drugs were advertised heavily before they went off patent, driving up brand loyalty and diminishing any shift in purchases due to generic entry.
} 
confirmed, we will have to find additional ways to distinguish among these hypotheses. Our fourth hypothesis predicts the opposite relationship:

Hypothesis IV: Brand-name prices to consumers matter greatly. Consumers view the quality differentials between brand-name and generic drugs as slight. Hence, price will be the determining factor in

generic substitution.

Implication of Hypothesis IV. Hypothesis IV predicts that consumers will first substitute generics for the most expensive brand-name drugs. This implies that the greater is generic scrip share, the lower will be average brand-name prices to consumers.

Our secondary empirical concern, mentioned earlier, is to determine how the relation between generic scrip share and average brand-name prices to consumers translates into average brand-name prices for health plans. To address this issue, we test Hypothesis $\mathrm{P}$, where $\mathrm{P}$ stands for plan.

Hypothesis P: If generic scrip share lowers (raises) average brand price to the consumer, it will lower (raise) the cost to health plans as well.

Before testing these hypotheses, we describe our data and estimation approach.

\section{DATA AND ESTIMATION}

$\underline{\text { Data }}$

This study uses data from the Medical Expenditure Panel Survey (MEPS). This database, cosponsored by the Agency for Healthcare Research and Quality (AHRQ) and the National Center for Health Statistics (NCHS), provides nationally representative estimates of medical treatments, pharmaceutical and other health care expenditures, health status, health insurance coverage, and sociodemographic and socioeconomic characteristics for the civilian, noninstitutionalized population in 
the United States. ${ }^{32}$ Our sample includes adults aged 25-64, and covers the period 1996-2001. The MEPS validates information on medical care utilization by contacting health care providers and pharmacies identified by survey respondents.

The MEPS data incorporates a number of surveys. The MEPS Household Survey includes personyear information on health care utilization and expenditures, and socioeconomic and demographic factors. To this basic file, we linked information from the MEPS Prescribed Medicines and Medical Conditions databases. The Prescribed Medicines data includes drug-specific information on utilization, numbers of prescriptions filled, and both patient and insurer expenditures. Because this database includes National Drug Codes (NDCs), a standardized product identifier for drugs for humans, we could distinguish between brand-name and generic drugs. The Medical Conditions data includes information on specific illnesses, which allowed us to identify drug use for common medical conditions. Using these databases, we are able to construct measures of annual numbers of prescriptions filled, out-of-pocket prices per drug, and patient costs for all brand-name and generic drugs in the database.

The MEPS database has a complex survey design which, beyond stratifying by sampling units, includes clustering, and oversampling of certain subgroups such as minorities. Therefore, all our statistical analyses use weights provided in MEPS to correct mean values.

$\underline{\text { Estimation }}$

We estimate empirical models relating the proportion of prescriptions filled by generics to consumer out-of-pocket prices for brand-name drugs, net brand-name prices paid by the insurer (i.e., the insurer's cost less the copay), and overall brand-name prices. In addition to generic scrip shares, our

\footnotetext{
${ }^{32}$ The MEPS sample was chosen as a nationally representative sub sample of the ongoing National Heath Interview Survey (NHIS) conducted by the National Center for Health Statistics. It is able to be linked to the NHIS database as well. The MEPS survey respondents were interviewed in person. The surveys achieve response rates of about $75 \%$. See Cohen, Joel, Monheit, Alan , and Beauregard, Karen. "The Medical Expenditure Panel Survey: A National Health Information Resource." Inquiry 33 no. 4 (1996): 373-389 for further details.
} 
models control for a variety of sociodemographic and health status measures that could affect the average purchase price of drugs.

The generic scrip share is endogenous; it is determined by some of the same factors that determine the average price of a brand-name drug to a patient. To overcome the resulting identification problem, we need to find instruments for generic scrip share. Thus we estimate a two-equation structural model. In the first stage of this model, we estimate the individual's generic scrip share as a function of both a vector of sociodemographic and health factors, and of several instruments that help to predict generic scrip share:

(5) $\operatorname{lnGENSCRIPSHR}=\alpha+\boldsymbol{\psi S O C I O D E M}+\boldsymbol{\theta H E A L T H}+\mathbf{\Omega Z}+\varepsilon$, where

lnGENSCRIPSHR = natural logarithm of scrips filled for generics divided by total scrips filled by the consumer;

SOCIODEM = a vector of socioeconomic and demographic factors;

HEALTH $\quad=\quad$ a vector of health status measures;

$\mathbf{Z}=\quad$ a vector of instruments that help identify the generic scrip share equations;

$\alpha, \boldsymbol{\psi}, \boldsymbol{\theta}, \mathbf{\Omega}, \quad=\quad$ coefficients to be estimated; and

$\varepsilon, \quad=\quad$ an error term.

The predicted values of lnGENSCRIPSHR will be used as an explanatory variable in second-stage price equations:

(6) $\operatorname{lnBRDPRICE}=\beta+\gamma \operatorname{lnGENSCRIPSHR}+$ ISOCIODEM +

\section{Ф HEALTH $+\mu$,}

where

lnBRDPRICE $\quad=\quad$ the natural logarithm of the average price of brand drugs; 


$$
\begin{array}{lll}
\beta, \gamma, \Pi, \boldsymbol{\Phi} & = & \text { coefficients to be estimated; } \\
\mu & = & \text { an error term; }
\end{array}
$$

and other variables are as defined above. Similar equations will be estimated for the average price of brand-name drugs paid for by the insurer (InINSBRDPRICE) and by the consumer (lnSLFBRDPRICE). Variables

Instruments. To avoid including endogenous factors in generic scrip share as an independent variable, we estimate that quantity using instrumental variables. Proper instruments will allow us to obtain unbiased estimates of the effect of generic scrip share on the average price of brand-name drugs. Our choice of instruments include market-level measures of scrip share, and demographic characteristics that may reflect an individual's preferences for or access to generic drugs. Our first instrument is the share of generic scrips in the subject's market area. We expect market share to be positively related to individual generic scrip shares. ${ }^{33}$ Although MEPS does not reveal geographic locations, the MEPS database is drawn from approximately 200 distinct, primary sampling units, which are identified by number. These units are counties or clusters of contiguous counties, and are stratified by census region and state urban status, and sociodemographic characteristics. ${ }^{34}$ Given this feature of MEPS, we are able to construct market-level measures of particular variables of interest, such as the generic scrip share in the market. These shares should be larger, for example, in markets located in states with laws that encourage generic substitution. A market-level measure of generic scrip share provides a proxy for such laws.

\footnotetext{
${ }^{33}$ One might argue that market-level measures of generic scrip share will affect brand prices directly, perhaps because producers of brand-name drugs have less ability to negotiate favorable prices in markets where generic scrip share is greater. As shown in Appendix B, however, we find no evidence of such direct effects of generic scrip share on the prices of brandname drugs.

${ }^{34}$ See Cohen, Joel. "Sample Design of the 1996 Medical Expenditure Panel Survey Household Component." MEPS Methodology Report No. 2 AHCPR Pub. No. 97-0027. Rockville, MD: Agency for Health Care Policy and Research (1997).
} 
A variety of research has found that consumers' attitudes toward generic drugs differ by age, education, race, and ethnicity. ${ }^{35}$ For example, Kendall et al. ${ }^{36}$ report that older consumers were less willing to substitute generic drugs when offered the choice. Perhaps they are more resistant to changing to newer drug alternatives. Possibly they are more wary about the quality of generics. Perri et al. ${ }^{37}$ note for example that consumers over age fifty were more concerned about the side effects of generics.

Education-specific differences in information about generics may affect people's choices. In a similar vein, race and ethnicity may affect generic scrip share if such differences reflect different information sets, access to or susceptibility to advertisements for brand-name drugs, or confidence in the quality of generics. Minorities and subjects with less education have generally been found to have more negative attitudes toward generics, implying that they would use them less. ${ }^{38}$ Yet, these groups also tend to have fewer resources, which may tilt toward generics.

This evidence suggests that variables measuring subject's age, education, race and ethnicity may usefully predict generic drug use. In contrast, there is little reason to expect these variables to have a strong independent effect on price, especially when one controls for income and health status, as our empirical models do. To illustrate, in preliminary empirical testing we found that age was strongly negatively related to generic scrip share, but we found no evidence that it had a direct effect on any of the price measures we consider. Thus, age performs well as an instrument. Similarly, preliminary statistical testing revealed that education as well as race-and-ethnicity indicators were strongly associated with generic scrip share, but had little direct relation to prices, implying that they too are effective instruments.

\footnotetext{
${ }^{35}$ See Gaither et al., supra note 26.

${ }^{36}$ See Kendall Kenneth W., Ng S, Schoner, Bertram.” "Consumer Response to Generic/chemically Equivalent Drugs.” Journal of Public Policy Marketing 10 (1991): 182-201.

${ }^{37}$ See Perri, Matthew, Wolfgang A, Janket C. (1990). "Georgia Consumers' Awareness and Perceptions of Generic Drugs after the Scandals." American Pharmacy NS30 no. 10 (1990): 33-36.

38 See Gaither et al., supra note 26.
} 
Our main results use the market level measure of generic scrip share and age as the sole instruments. These results are compared with those using, respectively, education and race-and-ethnicity measures instead of age as instruments, and then regressions that include all of these instruments, to check the robustness of our findings.

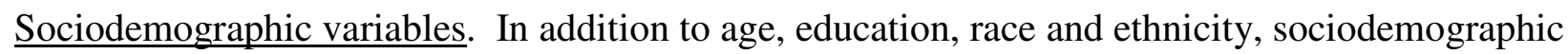
factors include gender, income, marital status, and health insurance status. These variables are intended to capture differences in information, preferences, and ability to pay for pharmaceutical treatments. We also include dummy variables indicating census region and urban/rural status of subject's residence, to capture geographic factors that might affect the availability and mix of generics as well as average prices. Year dummies are employed to control for intertemporal changes in nominal prices.

$\underline{\text { Health measures. }}$ Health indicators include the subject's self-assessed health status and binary variables for twelve common medical conditions. Table 1 provides the names, descriptions, and summary statistics of the variables used in this analysis.

\section{(INSERT TABLE 1)}

\section{RESULTS}

We begin with simple correlations between generic scrip share and the average price of prescriptions filled with brand-name drugs. As Table 2 indicates, generic scrip share is unrelated to the price paid by insurers. In contrast, we find a negative and highly significant correlation between generic scrip share and consumer out-of-pocket prices for brand-name drugs. The correlation between scrip share and overall price is also negative and significant, though the magnitude of this association is less than $40 \%$ as large as for out-of-pocket prices.

(INSERT TABLE 2) 
The patterns revealed from these simple correlations are consistent with our Hypothesis IV, namely that consumers choose generic drugs to lower their out-of-pocket costs for the mix of brand-name drugs they do purchase. Consider, for example, a consumer who purchases two brand-name drugs, one with an out-of-pocket cost of $\$ 10$ and one with an out-of-pocket cost of $\$ 25$. If he substitutes a generic for the $\$ 25$ drug, but not the $\$ 10$ drug, he will produce the pattern we observe: more generic scrips and a lower average brand-name price.

An alternative explanation for the negative correlation we observe is that it is an artifact of a range of econometric issues, such as selection effects, implying that the pattern should vanish in multivariate analyses that deal with identification issues. We turn now to conduct those analyses.

\section{Multivariate evidence}

Two-stage least squares estimates predicting generic market share indicate that the instruments we used -- market-level measures of generic scrip share and subject's age -- performed well. (See Appendix A.) Age in particular has a strong and highly significant negative effect on generic scrip share.

Do increases in the share of scrips that consumers fill with generics affect the average price that consumers pay for brand-name drugs? Table 3, which shows the results of the structural model described above, indicates that a higher generic scrip share produces a large and statistically significant decline in consumers' out-of-pocket prices. In particular, a 10\% increase in generic scrip share produces a $15.6 \%$ decline in the average consumer's out-of-pocket cost per scrip for the remaining brand-name drugs. In contrast, we find no statistically significant effect of scrip share on the average net prices to insurers. Overall prices decline significantly, overwhelmingly because of the strong negative effect on consumers' out-of-pocket costs. These multivariate results are consistent with the simple correlations presented above. 
The effects of generic scrip share were much smaller for insurers than for consumers, and statistically insignificant. Insurers may be able to promote generic choice so as to reduce their overall prescription costs, but they prove unable to simultaneously lower the average cost to themselves of the brand-name drugs that are purchased. This is not surprising given that the out-of-pocket drug costs per scrip and insurer costs per scrip are negatively correlated $(\mathrm{rho}=-0.22 ; \mathrm{p}<0.0001) .{ }^{39}$ But the far larger percentage reductions in out-of-pocket cost savings to consumers may also reflect the structure of multi-tiered insurance for prescribed medicines, as well as the fact that percentage differences in prices among brandname drugs are typically small relative to differences in prices between brand-names and generics.

To illustrate, consider a typical three-tiered plan, in which the consumer must pay $\$ 5$ if he selects a generic, $\$ 10$ if he selects a preferred brand drug, and \$25 if he chooses a brand drug that is not preferred. For ease of exposition, assume that this consumer currently purchases 1 preferred brand-name drug (total price \$80) and 1 non-preferred brand-name drug (total price \$120). Suppose that this consumer then substitutes a generic drug for the non-preferred brand-name drug. Then this consumer's average out-ofpocket price for brand drugs will fall substantially in percentage terms - from $\$ 17.50$ to $\$ 10$, or a $43 \%$ decline. But the percentage reduction in terms of average net brand-name prices paid by the insurer will be much less, from $\$ 82.50$ - i.e., $(\$ 80-\$ 10+\$ 120$ - $\$ 25) / 2$-- to $\$ 70$, or just a $15 \%$ reduction.

Other results indicate that people in better overall health and people with public insurance buy a less expensive mix of brand-name drugs. Women buy a less expensive mix as well; precisely why is not clear. It may reflect their tendency to use health care, including drug therapy, more extensively (Center on an Aging Society 2002), ${ }^{40}$ while males may tend to restrict drug treatments to more serious conditions, which tend to require more expensive pharmaceuticals.

\footnotetext{
${ }^{39}$ In contrast, overall price and out-of-pocket cost per scrip are strongly positively correlated $($ rho $=0.76 ; \mathrm{p}<0.0001)$.

${ }^{40}$ See Center on an Aging Society. "Prescription Drugs: A Vital Component of Health Care." Washington DC: Georgetown University (2002).
} 
(INSERT TABLE 3)

The results of a number of alternative specifications are summarized in Table 4. These alternative estimates employ different sets of instruments from the age, education, and race and ethnicity variables discussed above. Thus they provide a sense of the robustness of our results to alternative structural model specifications. The first column in the table estimates the effects of generic scrip share using the same models reported in Table 3. Column 2 (2SLS II) uses educational attainment measures instead of age as instruments, while column 3 (2SLS III) uses race and ethnicity measures. Column 4 (2SLS IV) uses all of these variables as instruments (e.g., the market-level measure of generic scrip share, age, educational attainment, race, and ethnicity).

\section{(INSERT TABLE 4)}

The results of these alternative models are strongly consistent. In each case, generic scrip share has a strong negative relationship with consumers' out-of-pocket costs. In contrast, the estimated effects on prices paid by insurers are substantially smaller in magnitude and statistically insignificant in all models. The effect on out-of-pocket costs is strong enough that it leads to significantly lower overall prices as well.

$\underline{\text { Tests of Hypotheses. }}$ These results lead us to reject Hypotheses I-III, since the implication of those hypotheses was refuted. The results strongly support the implication of Hypothesis IV, thus providing evidence for it. Brand-name prices to consumers matter greatly.

Since we did not examine consumers' decisions directly, e.g., by observing how they traded off quality and cost, some other explanation could conceivably be found for the pattern we observe. In 
contrast, though we find some evidence that is consistent with Hypothesis $\mathrm{P}$, these findings are statistically insignificant in all specifications. ${ }^{41}$

Finally, the last column provides ordinary least squares (OLS) results. These results are also consistent with the 2SLS estimates, though the estimated magnitudes are considerably smaller in absolute value. This could reflect two factors. First, measurement error in the generic scrip share may be greater in the OLS estimates, which would bias the estimated coefficient downward. Second, and perhaps more importantly, consumers facing higher prices for brand-name drugs may use fewer of them, leading to a higher generic scrip share. This "reverse-causation" effect would bias OLS results toward finding a positive association between scrip share and average brand-name price. In short, OLS methods can not reliably answer our primary questions. Our instrumental variables approach is designed to overcome this upward bias, and indeed we find a stronger negative association in all of the estimates using this method.

\section{CONCLUSION}

This paper sought to gain a fuller understanding of how generic scrip share affects the price of brand-name drugs consumers buy. Most previous research has established that competition from generics does not induce producers of brand-name drugs to lower their prices (a finding that we reinforce), but it has not considered how consumer choices might influence the average prices of the brand-name drugs consumers do buy. Since generics enable consumers to avoid buying the brand-name drugs they pay the most for, that effect could be substantial, and so it proves to be. We find that the average price paid by consumers for brand-name drugs falls substantially when generic scrip share rises: a 10\% increase in consumers' generic scrip share is associated with a $15.6 \%$ decline in the average price paid for brandname drugs by consumers. The patterns we observe are consistent with a model where consumers value

41 See Appendix B2. It explains a bias introduced because brand-name drugs without generic substitutes sell for higher prices to insurers. This bias makes it less likely that consumer choice will produce a negative correlation between generic scrip share 
the cost savings from generic purchases more than any perceived quality premiums offered by brandname drugs. In contrast, we find little evidence that insurers have been able to change the mix of drugs purchased by consumers so as to lower their own average brand-name costs.

Our results suggest that the potential cost savings to consumers from generic drugs may be far greater than previous work might suggest. Not only does the consumer benefit from the lower generic prices, but also the pattern of switching lowers the average purchase price of branded drugs. Moreover, during the period of our analysis, the average generic scrip share across markets was only $43 \%-47 \%,{ }^{42}$ suggesting that generic substitution has considerable future potential to lower the average prices of brandname drugs.

While our results suggest that legal and other barriers to further growth in generics merit even greater scrutiny, we must emphasize that our study is not a welfare analysis of the merits or consequences of generic drugs. Regulators such as the Food and Drug Administration (FDA) must weigh generic applications carefully; for some types of drugs, particularly those which are safe only within a narrow dosage range, quality considerations may be paramount. An additional factor from a welfare perspective concerns whether increased purchases of generics will reduce the funds available for $R \& D$, the vast majority of which are financed by producers of brand-name drugs. This issue must also be considered in gauging the full social welfare effects of greater generic scrip share, particularly for a large nation that is also a major pharmaceutical manufacturer.

Despite the evidence suggesting that consumers and their physicians face substantial information deficits about the prices of alternative drugs, the present study indicates that where consumers generate a greater use of generics, they adjust their prescription portfolios to lower the average prices they pay for brand-name drugs.

and average brand-name cost to insurers.

${ }^{42}$ See Pharmaceutical and Research Manufacturers of America, supra note 1. 
As the nation grapples with the problem of controlling escalating health care costs, market-driven versus centralized approaches are being increasingly debated. To better inform this debate, evidence is needed on the effectiveness of alternative approaches at achieving cost control. The present study provides evidence that consumers choose generic over brand name drugs where they save the most money. 


\section{Bibliography}

Berndt, Ernst R. "Pharmaceuticals in U.S. Health Care: Determinants of Quantity and Price." Journal of Economic Perspectives 16 no. 4 (2002): 45-66.

Caves, Richard E., Whinston, Michael D., and Hurwitz, Mark A. "Patent Expiration, Entry, and Competition in the U.S. Pharmaceutical Industry." Brookings Papers on Economic Activity:

Microeconomics (1991), pp. 1-48.

Center on an Aging Society. "Prescription Drugs: A Vital Component of Health Care." Washington DC: Georgetown University (2002).

Cohen, Joel. "Sample Design of the 1996 Medical Expenditure Panel Survey Household Component." MEPS Methodology Report No. 2 AHCPR Pub. No. 97-0027. Rockville, MD: Agency for Health Care Policy and Research (1997).

Cohen, Joel, Monheit, Alan, and Beauregard, Karen. "The Medical Expenditure Panel Survey: A National Health Information Resource.” Inquiry 33 (2002): 373-389.

Congressional Budget Office. "How Increased Competition from Generic Drugs Has Affected Prices and Returns in the Pharmaceutical Industry." Washington, DC: Congressional Budget Office (1998).

Frank, Richard G., and Salkever, David S. "Generic Entry and the Pricing of Pharmaceuticals." Journal of Economics and Management Strategy. 6 (1997): 75-90.

Gaither C, Kirking D, Ascione F, et al. "Consumer's Views on Generic Medications.” Journal of the American Pharmacy Association 41 no. 5 (2001): 729-736.

Ganther, Julie M., and Kreling, David H. (2000). "Consumer Perceptions of Risk and Required Cost Savings for Generic Prescription Drugs." Journal of the American Pharmacy Association 40 (2000): 378383.

Gaynor, Martin, and Polachek, Solomon W. "Measuring Information in the Market: An Application to Physician Services." Southern Economic Journal 60 no. 4 (1994): 815-831.

Grabowski, Henry G., and Vernon, John M. "Brand Loyalty, Entry, and Price Competition in Pharmaceuticals after the 1984 Drug Act". Journal of Law and Economics 35 (1992): 331-350..

Hibbard, Judith H., and Weeks, Edward C. "Consumerism in Health Care: Prevalence and Predictors." Medical Care 25 no. 11 (1987): 1019-1032.

Hibbard, Judith H., and Weeks, Edward C. "Does the Dissemination of Comparative Data on Physician Fees Affect Consumer Use of Services?" Medical Care 27 no. 12 (1989): 1167-1174.

Kaiser Family Foundation. "Prescription Drug Trends." Washington, DC: Kaiser Family Foundation (2004). 


\section{Bibliography}

Kendall Kenneth W., Ng S, Schoner, Bertram." "Consumer Response to Generic/chemically Equivalent Drugs." Journal of Public Policy Marketing 10 (1991): 182-201.

Meier, Markus H. “The FTC's Pharmaceutical Industry Cases.” California Bar Association (2002). Document available at: www.calbar.ca.gov/calbar/pdfs/sections/antitrust/2002-06-26_genericdrug_materials-meier.pdf.

NIHCM Foundation (National Institute for Health Care Management Research and Educational Foundation). . "A Primer: Generic Drugs, Patents, and the Pharmaceutical Market Place." Washington, DC: NICHM Foundation (2002). Accessed at: http://www.nihcm.org/GenericsPrimer.pdf.

Office of Technology Assessment. "Pharmaceutical R\&D: Costs, Risks and Rewards ." Washington, DC: Office of Technology Assessment (1993).

Perri, Matthew, Wolfgang A, Janket C. (1990). "Georgia Consumers' Awareness and Perceptions of Generic Drugs after the Scandals." American Pharmacy NS30 no. 10 (1990): 33-36.

Pharmaceutical Research and Manufacturers of America. "A Century of Progress." Washington, DC: Pharmaceutical Research and Manufacturers of America (2001).

Silcock J, Ryan M, Bond C, et al. (1997). "The Cost of Medicines in the United Kingdom: A Survey of General Practitioners' Opinions and Knowledge." PharmacoEconomics 11 no. 1 (1997): 56-63.

Wiggins, Steven N., and Maness, Robert S. "Price Competition in Pharmaceuticals: The Case of Antiinfectives." Economic Inquiry 42 no. 2 (2004): 247-263. 
Table 1. VARIABLE NAMES, DESCRIPTIONS, AND SUMMARY STATISTICS

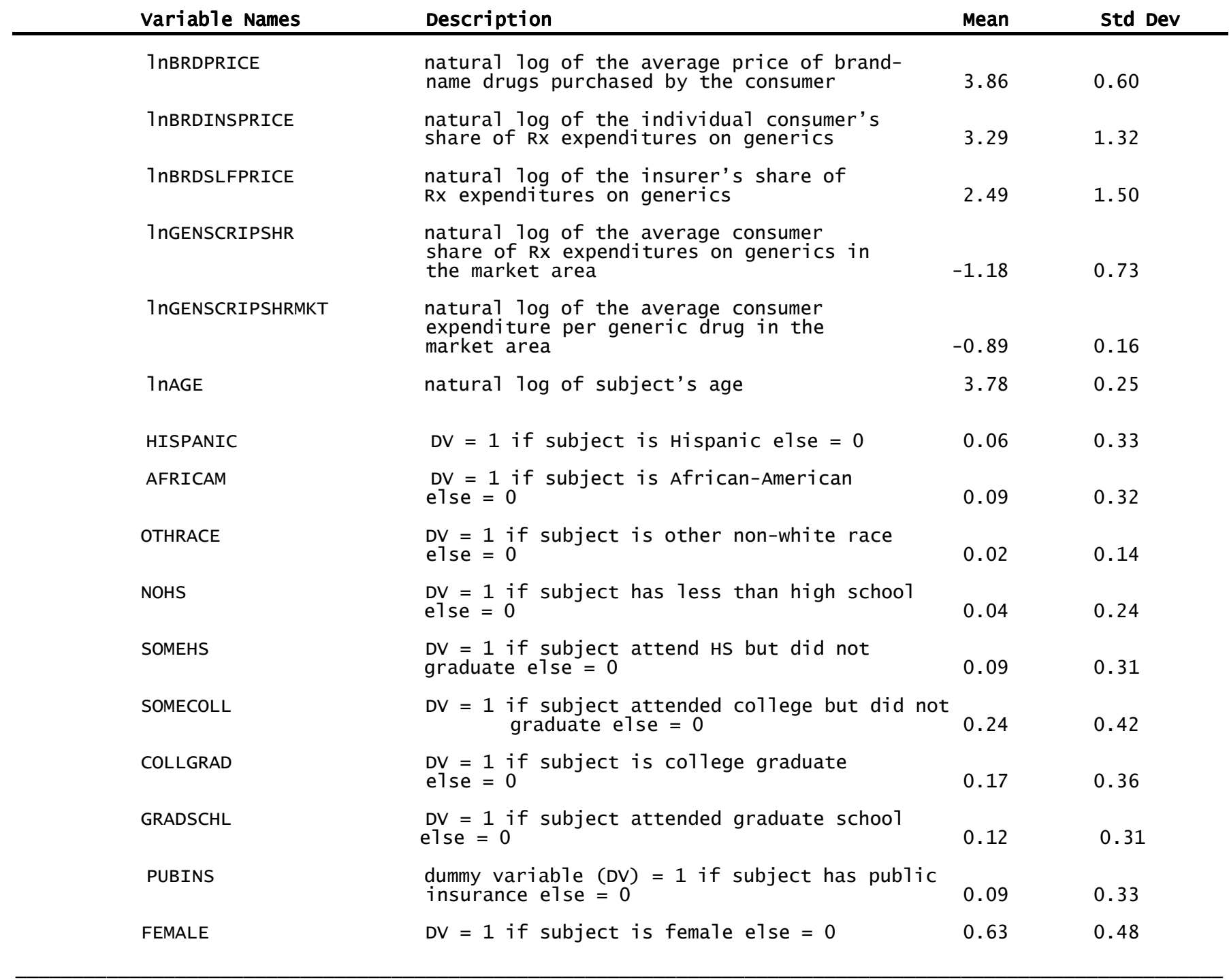

Table 1. VARIABLE NAMES, DESCRIPTIONS, AND SUMMARY STATISTICS

Variable Names

INCLT10K

INC2030K

INC3050K

INC50KUP

MARRIED

HEALTHFAIR
$D V=1$ if subject's income 1ess than $\$ 10,000$

$$
\text { else }=0
$$

0.06

0.25

DV $=1$ if subject's income $\$ 20 k-\$ 30 k$ else $=0$

0.10

0.31

DV $=1$ if subject's income $\$ 30 k-\$ 50 k$ else $=0$

0.23

0.43

$\mathrm{DV}=1$ if subject's income $\$ 50 \mathrm{k}$ and up

$$
\text { else }=0
$$

0.53

0.50

DV $=1$ if subject is married else $=0$

0.73

0.44

$D V=1$ is subject's health is fair else $=0$

0.17

0.39 


\begin{tabular}{|c|c|c|c|}
\hline HEALTHGOOD & $\mathrm{DV}=1$ if subject's health is good else $=0$ & 0.37 & 0.48 \\
\hline HEALTHVGOOD & $\begin{array}{l}\text { DV }=1 \text { if subject's health is very good } \\
\text { else }=0\end{array}$ & 0.32 & 0.45 \\
\hline HEALTHEXC & $\begin{array}{l}\text { DV }=1 \text { if subject's health is excellent } \\
\text { else }=0\end{array}$ & 0.08 & 0.25 \\
\hline HTN & $D V=1$ if subject has hypertension else $=0$ & 0.26 & 0.45 \\
\hline LIPID & $\begin{array}{l}\text { DV }=1 \text { if subject has 1ipid disorder } \\
\text { else }=0\end{array}$ & 0.11 & 0.32 \\
\hline THYROID & $\begin{array}{l}\text { DV }=1 \text { if subject has thyroid disorder } \\
\text { else }=0\end{array}$ & 0.08 & 0.28 \\
\hline ASTHMA & $D V=1$ if subject has asthma else $=0$ & 0.07 & 0.27 \\
\hline RESP & $\begin{array}{l}\text { DV }=1 \text { if subject has respiratory disorder } \\
\text { else }=0\end{array}$ & 0.22 & 0.41 \\
\hline DIABETES & $\mathrm{DV}=1$ if subject has diabetes else $=0$ & 0.07 & 0.28 \\
\hline ANXIETY & $\begin{array}{l}\text { DV }=1 \text { if subject has anxiety disorder } \\
\text { else }=0\end{array}$ & 0.11 & 0.31 \\
\hline AFFECTIVE & $\begin{array}{l}\text { DV }=1 \text { if subject has affective disorder } \\
\text { else }=0\end{array}$ & 0.02 & 0.14 \\
\hline OTHMENT & $\begin{array}{l}\text { DV }=1 \text { if subject has other mental disorder } \\
\text { else }=0\end{array}$ & 0.16 & 0.37 \\
\hline
\end{tabular}

Table 1. VARIABLE NAMES, DESCRIPTIONS, AND SUMMARY STATISTICS

HEADACHE

JOINT

BACK

MIDWEST

SOUTH

WEST

URBAN

YR1997

YR1998

YR1999

YR2000

YR2001
DV $=1$ if subject has persistent headache else $=0$

0.11

0.32

DV $=1$ if subject has chronic joint pain else $=0$

0.15

0.37

DV $=1$ if subject has chronic back pain else $=0$

0.17

0.38

$\mathrm{DV}=1$ if subject lives in Midwest Census Region else $=0$

0.25

0.43

DV $=1$ if subject 1ives in south Census Region else $=0$

0.37

0.49

$\mathrm{DV}=1$ if subject 1ives in west Census Region else $=0$

0.19

0.40

DV $=1$ if subject lives in metropolitan statistical area else $=0$

0.80

0.42

$\mathrm{DV}=1$ if year is 1997 else $=0$

0.15

0.40

$\mathrm{DV}=1$ if year is 1998 else $=0$

0.17

0.36

$\mathrm{DV}=1$ if year is 1999 else $=0$

0.17

0.36

$\mathrm{DV}=1$ if year is 2000 else $=0$

0.16

0.35

$\mathrm{DV}=1$ if year is 2001 else $=0$

0.18

0.41 
Table 2: Correlations between Generic Scrip Share and Brand-name Drug Prices

PRICE MEASURE

TOTAL PRICE

INSURER PRICE

OUT-OF-POCKET

$-0.06 * * * \quad 0.005$

PRICE

GENERIC SCRIP

$-0.06 \% *$

0.005

$-0.14 * * *$

SHARE

$* * * \quad$ Statistically significant at the $1 \%$ leve1, two-tailed test. 
Table 3: Generic Scrip Share and Brand-name Drug Prices

(2SLS estimation; $n=16,609$ )

DEPENDENT VARIABLE

\begin{tabular}{|c|c|c|c|}
\hline VARIABLE & TOTAL PRICE & INSURER PRICE & $\begin{array}{l}\text { OUT-OF-POCKET } \\
\text { PRICE }\end{array}$ \\
\hline $\begin{array}{l}\text { INTERCEPT } \\
\text { 1nGENSCRIPSHR } \\
\text { PUBINS } \\
\text { FEMALE } \\
\text { INCLT10K } \\
\text { INC2030K } \\
\text { INC3050K } \\
\text { INC50KUP } \\
\text { HISPANIC } \\
\text { AFRICAM } \\
\text { OTHRACE } \\
\text { NOHS } \\
\text { SOMEHS } \\
\text { SOMECOLL } \\
\text { COLLGRAD } \\
\text { GRADSCHL } \\
\text { MARRIED } \\
\text { HEALTHFAIR } \\
\text { HEALTHGOOD } \\
\text { HEALTHVGOOD } \\
\text { HEALTHEXC } \\
\text { HTN } \\
\text { LIPID } \\
\text { THYROID } \\
\text { ASTHMA } \\
\text { RESP } \\
\text { DIABETES } \\
\text { ANXIETY } \\
\text { AFFECTIVE } \\
\text { OTHMENT } \\
\text { HEADACHE } \\
\text { JOINT } \\
\text { BACK } \\
\text { MIDWEST } \\
\text { SOUTH } \\
\text { WEST } \\
\text { URBAN } \\
\text { YR1997 } \\
\text { YR1998 } \\
\text { YR1999 } \\
\text { YR2000 } \\
\text { YR2001 }\end{array}$ & $\begin{array}{l}3.06 * * * \\
-0.87 * * * \\
0.17 * * * \\
-0.231 * * * \\
-0.012 \\
0.01 \\
-0.02 \\
-0.01 \\
0.02 \\
0.005 \\
0.02 \\
0.02 \\
-0.03 \\
-0.02 \\
-0.06 * * \\
-0.01 \\
-0.04 * * * \\
-0.09 * * * \\
-0.16 * * * \\
-0.19 * * * \\
-0.25 * * * \\
-0.03 \\
0.04 \\
-0.36 * * * \\
0.03 \\
-0.05 * * \\
-0.14 * * * \\
0.09 * * * \\
0.12 * * * \\
0.04 \\
0.04 * * \\
0.02 \\
-0.003 \\
-0.05 * * \\
-0.10 * * * \\
-0.01 \\
-0.01 \\
0.08 * * * \\
0.13 * * \\
0.28 * * * \\
0.25 * * * \\
0.39 * * *\end{array}$ & $\begin{array}{l}2.80 * * * \\
-0.33 \\
0.14 * * * \\
-0.23 * * * \\
0.10 * * \\
-0.02 \\
0.03 \\
0.05 \\
0.02 \\
-0.02 \\
0.004 \\
0.01 \\
-0.03 \\
-0.01 \\
-0.05 \\
-0.01 \\
-0.05 * * \\
0.03 \\
-0.02 \\
-0.06 \\
-0.16 * * \\
0.03 \\
0.20 * * * \\
-0.42 * * * \\
0.05 * * \\
0.06 \\
-0.05 \\
0.13 * * * \\
0.23 * * * \\
0.14 * * * \\
0.08 * * * \\
-0.01 \\
-0.01 \\
-0.07 * * \\
-0.12 * * * \\
-0.06 * * \\
0.07 * * * \\
0.11 * * * \\
0.15 * * * \\
0.37 * * * \\
0.30 * * * \\
0.48 * * * \\
\end{array}$ & $\begin{array}{l}1.19 * * * \\
-1.56 * * * \\
-0.46 * * * \\
-0.18 * * * \\
-0.23 * * * \\
-0.04 \\
-0.12 \\
-0.15 * * * \\
0.05 \\
0.01 \\
0.01 \\
-0.05 \\
-0.09 * * * \\
-0.02 \\
-0.04 \\
-0.02 \\
0.02 \\
-0.22 * * * \\
-0.31 * * * \\
-0.31 * * * \\
-0.29 * * * \\
-0.06 * * \\
-0.18 * * * \\
-0.26 * * * \\
-0.10 * * \\
-0.14 * * * \\
-0.20 * * * \\
0.02 \\
-0.12 \\
-0.14 * * * \\
0.02 \\
0.04 \\
0.03 \\
-0.05 \\
0.02 \\
0.06 \\
-0.05 * * \\
0.04 \\
0.11 * * * \\
0.22 * * * \\
0.28 * * * \\
0.35 * * *\end{array}$ \\
\hline
\end{tabular}

$* * * \quad$ Statistically significant at the $1 \% 1$ eve1, two-tailed test.

$* * \quad$ Statistically significant at the $5 \%$ leve1, two-tailed test. 
Table 4. Alternative Models of Generic Expenditure Share and the Price of Brand-name drugs*

TOTAL PRICE

$\begin{array}{lllll}\text { VARIABLE } & \text { 2SLS I } & \text { 2SLS II } & \text { 2SLS III } & \text { 2SLS IV }\end{array}$

InGENSCRIPSHR $\quad-0.87 * * * \quad-0.58 * * * \quad-0.77 * * * \quad-0.69 * * * \quad-0.03 * * *$

INSURER PRICE

$\begin{array}{lllll}\text { VARIABLE } & \text { 2SLS I } & \text { 2SLS II } & \text { 2SLS III } & \text { 2SLS IV }\end{array}$

$\begin{array}{llllll}\text { InGENSCRIPSHR } & -0.33 & -0.13 & -0.44 & -0.26 & 0.02\end{array}$

\section{OUT-OF-POCKET PRICE}

$\begin{array}{lllll}\text { VARIABLE } & \text { 2SLS I } & \text { 2SLS II } & \text { 2SLS III }\end{array}$

InGENSCRIPSHR $-1.56 * * * \quad-1.66 * * * \quad-1.38 * * * \quad-1.47 * * * \quad-0.13 * * *$

* The first column in Table 4 provides the estimated effects of generic scrip share using the same models reported in Table 3. The second column (2SLS II) uses educational attainment instead of age as an instrument. Column III (2SLS III) uses race/ethnicity measures instead of age as instruments. Column IV (2SLS IV) uses the market leve1 measure of generic scrip share, age, educational attainment, and race/ethnicity measures as instruments. 


\section{Appendix A: Generic Scrip Share Equation Estimate}

Table A1. Generic Scrip Share Equation Estimate

$(2 S L S ; n=16,609)$

DEPENDENT VARIABLE: GENRIC SCRIP SHARE

VARIABLE

\begin{tabular}{|c|c|}
\hline INTERCEPT & $-0.37 * * *$ \\
\hline InGENSCRIPSHRMKT & 0.05 \\
\hline 1nAGE & $-0.11 * * *$ \\
\hline HISPANIC & $0.08 * * *$ \\
\hline AFRICAM & $0.09 * *$ \\
\hline OTHRACE & $0.10 \% *$ \\
\hline NOHS & 0.04 \\
\hline SOMEHS & 0.03 \\
\hline SOMECOLL & $-0.04 * *$ \\
\hline COLLGRAD & $-0.07 * * *$ \\
\hline GRADSCHL & $-0.07 * *$ \\
\hline PUBINS & $0.11 * * *$ \\
\hline FEMALE & $-0.13 * * *$ \\
\hline INCLT10K & -0.04 \\
\hline INC2030K & -0.03 \\
\hline INC3050K & -0.02 \\
\hline INC50KUP & -0.03 \\
\hline MARRIED & -0.01 \\
\hline HEALTHFAIR & $-0.11 * * *$ \\
\hline HEALTHGOOD & $-0.14 * *$ \\
\hline HEALTHVGOOD & $-0.11 *$ \\
\hline HEALTHEXC & $-0.08 *$ \\
\hline HTN & $-0.06 * *$ \\
\hline LIPID & $-0.17 * *$ \\
\hline THYROID & $-0.13 * * *$ \\
\hline ASTHMA & $-0.09 * *$ \\
\hline RESP & $-0.11 * *$ \\
\hline DIABETES & $-0.17 * * *$ \\
\hline ANXIETY & -0.04 \\
\hline AFFECTIVE & -0.07 \\
\hline OTHMENT & $-0.14 * * *$ \\
\hline HEADACHE & -0.02 \\
\hline JOINT & -0.001 \\
\hline BACK & 0.01 \\
\hline MIDWEST & -0.02 \\
\hline SOUTH & $-0.05 * *$ \\
\hline WEST & 0.04 \\
\hline URBAN & 0.01 \\
\hline YR1997 & 0.01 \\
\hline YR1998 & 0.02 \\
\hline YR1999 & 0.04 \\
\hline YR2000 & -0.002 \\
\hline YR2001 & $-0.05 * *$ \\
\hline
\end{tabular}

$* * * \quad$ Statistically significant at the $1 \%$ leve1, two-tailed test.

$*$ Statistically significant at the $5 \%$ leve1, two-tailed test. 


\section{Appendix B: Alternative potential effects of generic substitution on brand price}

B1. Generic scrip share and the prices charged for brand-name drugs.

A second question that arises is whether generic scrip share affects the prices companies charge for brandname drugs. We investigated this issue by including the market-level measure of generic scrip share -GENSCRIPSHRMKT-- directly in the price equations. The results, provided in Appendix Table B2 below, indicate that GENSCRIPSHRMKT had no statistically significant effect on any of the price measures. That individual generic scrip share has a strong negative effect on out-of-pocket costs and overall price independent of market-level scrip share indicates that this result does not simply reflect regional variations in scrip shares and prices.

B2. Relationship between brand-name prices and the presence of generic competitors.

A relationship between the prices of brand-name drugs and the presence of generic competitors might help to explain our results. For example, if those branded drugs that face generic competition had higher prices than branded drugs with no generic competitors, the negative association between generic scrip share and brand prices might simply reflect this price differential. To investigate this issue, we compared the overall prices, insurer prices, and consumer out-of-pocket prices for 25 commonly dispensed branded drugs that faced generic competition with 25 major branded drugs that did not face generic competition (the names and frequencies of scrips filled with these drugs is provided in Appendix Table B1). We found that branded drugs that faced generic competition had lower average prices than branded drugs with no generic competitors. ${ }^{43,44}$ To the extent this is the case, our estimated results are biased against finding a negative association between generic scrip share and the price of brand-name drugs, providing a strong test of the hypothesis that a greater generic scrip share leads to lower prices for brandname drugs. We also found that the both the percentage and absolute difference between prices for brand-name drugs without and with generic competition was greater for insurers than for consumers. That is, average net prices paid by insurers were substantially higher for brand drugs that did not face generic competition ( $\$ 63$ versus $\$ 48$ or 31\% higher), while the equivalent average out-of-pocket costs to consumers were more modestly higher (\$11 versus $\$ 9$ or $22 \%$ ). Thus, the bias against finding a negative relationship between scrip share and brand-name prices is greater for insurer prices, which could help explain the weaker negative association between generic scrip share and insurer prices. In any event, our results in the text strongly suggest that increases in generic scrip share substantially lower consumers' out-of- pocket costs and that this estimated relationship is a conservative one.

\footnotetext{
${ }^{43}$ The drugs examined are used to treat major conditions. Branded drugs with and without generic competitors were compared. Brand-name prices for drugs with generic competitors continued to be lower in multivariate regressions that controlled for medical conditions for which the drug in question was used.

${ }^{44} \mathrm{We}$ are only able to observe brand and generic drug prices for drugs actually purchased. Conceivably, the brand-name prices faced by people who selected the generic alternative may have been higher than the brand-name prices for those who bought the bran. Including this information, were it available, might reduce price disparities between branded drugs with and without generic competitors.
} 
Table B1. Generic Scrip share in the Market and the Price of Brand-name drugs*

VARIABLE

1nGENSCRIPSHR

1nGENSCRIPSHRMKT
TOTAL PRICE

$-0.81 * * *$

$-0.03$
INSURER PRICE

$-0.23$

$-0.05$
OUT-OF-POCKET PRICE

$-1.43 * * *$

$-0.06$

* These are 2SLS estimates, using 1nAGE as an instrument for 7nGENSCRIPSHR. 
Table B2. Brand-name drugs used in comparisons of prices by generic competition status

Brand-name drugs used in comparisons of prices by generic competition status Combined datasets

Brand-name drugs without generic competition

$\begin{array}{lrc}\text { Brand-name } & \text { \# scrips } & \text { \% of scrips } \\ \text { Accupril } & 7,202 & 6.5 \\ \text { Altace } & 2,657 & 2.4 \\ \text { Avandia } & 2,643 & 2.4 \\ \text { Azmacort } & 1,855 & 1.7 \\ \text { Celebrex } & 5,315 & 4.8 \\ \text { Celexa } & 1,944 & 1.7 \\ \text { Claritin } & 9,580 & 8.6 \\ \text { Effexor } & 1,427 & 1.3 \\ \text { Glucophage XR } & 186 & 0.2 \\ \text { Glucotrol XL } & 3,939 & 3.5 \\ \text { Imitrex } & 1,754 & 1.6 \\ \text { Lescol } & 3,520 & 3.2 \\ \text { Lipitor } & 21,138 & 19.0 \\ \text { Lotensin } & 4,984 & 4.5 \\ \text { Monopril } & 2,389 & 2.1 \\ \text { Plendil } & 2,258 & 2.0 \\ \text { Pravachol } & 662 & 0.6 \\ \text { Paxil } & 7,927 & 7.1 \\ \text { Theolair-SR } & 98 & 0.1 \\ \text { Toprol XL } & 4,205 & 3.8 \\ \text { Verelan PM } & 43 & 0.0 \\ \text { Vioxx } & 4,023 & 3.6 \\ \text { Wellbutrin SR } & 1,290 & 1.2 \\ \text { Zocor } & 13,826 & 12.4 \\ \text { Zyrtec } & 6,679 & 6.0\end{array}$


Table B2, cont.

Brand-name drugs with generic competition

Brand-name

Adalat CC

Aldactone

Buspar

Capoten

Corgard

Daypro

Elavil

Glucotrol

Klonopin

Lodine

Lasix

$\begin{array}{rc}\text { \# scrips } & \text { \% of scrips } \\ 2,812 & 3.3 \\ 454 & 0.5 \\ 2,280 & 2.7 \\ 926 & 1.1 \\ 294 & 0.3 \\ 1,883 & 2.2 \\ 796 & 0.9 \\ 1,128 & 1.3 \\ 948 & 1.1 \\ 1,058 & 1.2 \\ 3,233 & 3.8\end{array}$

Lopressor

Lozol

Mevacor

Micronase

Prinivil

Proventil

Prozac

Provera

Synthroid

Tenormin

Ventolin

Vasotec

Xanax

Zestril
1,468

588

2,510

793

6,261

2,478

10,159

2,305

18,408

1,440

2,713

6,750

1,482

12,202
1.7

0.7

2.9

0.9

7.3

2.9

11.9

2.7

21.6

1.7

3.2

7.9

1.7

14.3 